\title{
Electroanalytical and HPLC Methods for the Determination of Oxcarbazepine in Spiked Human Urine and Tablet Dosage Form
}

\author{
Agnieszka Nosal-Wierciñska, ${ }^{a}$ Selehattin Yilmaz,,${ }^{b, *}$ Sevcan Binel, ${ }^{b}$ Sultan Yagmur, ${ }^{\mathrm{b}}$ \\ Gulsen Saglikoglu, ${ }^{\mathrm{b}}$ Murat Sadikoglu, ${ }^{\mathrm{c}}$ and Mustafa Yıldiz ${ }^{\mathrm{b}}$ \\ ${ }^{a}$ Faculty of Chemistry, Maria Curie-Sk ${ }^{3}$ odowska University, 20-031 Lublin, Poland \\ ${ }^{\mathrm{b}}$ Canakkale Onsekiz Mart University, Faculty of Science and Arts, Department of Chemistry, 17020, Canakkale, Turkey \\ ${ }^{\mathrm{c}}$ Gaziosmanpasa University, Faculty of Education, Department of Science Education, 60100, Tokat, Turkey
}

RECEIVED JULY 14, 2012; REVISED APRIL 6, 2014; ACCEPTED JUNE 30, 2014

\begin{abstract}
In this study, the electrochemical reduction and determination of oxcarbazepine were easily realized in various buffer solutions in the $\mathrm{pH}$ range of 4.50 to 11.15 in real samples using glassy carbon electrode (GCE) by cyclic voltammetric (CV) and differential pulse voltammetric (DPV) techniques. The influence of $\mathrm{pH}$ on the cathodic peak current and peak potential was investigated. Scan rate studies were also completed. The diffusion controlled nature of the peak was established. The best results for the quantitative determination of oxcarbazepine were obtained by DPV technique in Britton-Robinson (BR) buffer ( $\mathrm{pH}$ 8.05). In this basic medium, one irreversible and sharp cathodic peak was observed. A linear calibration curve for DPV analysis was constructed in the oxcarbazepine concentration range of $8 \times 10^{-6}$ to $1 \times 10^{-4} \mathrm{M}$. Limit of detection (LOD) and limit of quantification (LOQ) were obtained as $1.65 \times 10^{-6}$ and $5.51 \times 10^{-6} \mathrm{M}$, respectively. Repeatability, reproducibility, precision and accuracy of the developed technique were checked in spiked human urine and tablet dosage forms by recovery studies and results of the high performance liquid chromatography (HPLC) technique. A reduction mechanism for the electrode reaction was proposed.
\end{abstract}

Keywords: oxcarbazepine, human urine, dosage form, electrochemical reduction, determination, high performance liquid chromatography (HPLC)

\section{INTRODUCTION}

Oxcarbazepine is an anticonvulsant and mood stabilizing drug, used primarily in the treatment of epilepsy (Scheme 1). It is also used to treat anxiety and mood disorders, and benign motor tics. The drug is administered both orally and intravenously. ${ }^{1,2}$

Oxcarbazepine was determined in pharmaceutical dosage forms and biological samples by chromatography ${ }^{1-7}$ and spectrophotometry ${ }^{8}$ techniques. However, these techniques are time consuming and have high cost.

So far, only a few papers have been published on the electroanalytical determination of oxcarbazepine based on its reduction behavior. ${ }^{1,2}$ However, the determination of oxcarbazepine on glassy carbon electrode (GCE) based on its detailed electrochemical reduction behavior and determination in real samples has not been reported to date. In this study, reduction and the determination of oxcarbazepine was realized in spiked human urine and tablet dosage forms.
The CV technique is one of the most advanced and most sensitive electroanalytical techniques. It combines the advantages of the pulse voltammetric techniques capable of discriminating against the capacitive current and the cyclic voltammetry techniques that provide an insight into the mechanism of the electrode reaction. In addition, this technique is particularly well suited for quantitative determination of the redox couples immobilized on the electrode surface. ${ }^{9-12}$ Another important advantage of these proposed techniques over other techniques is that they can be applied directly to the analysis of pharmaceutical dosage forms and

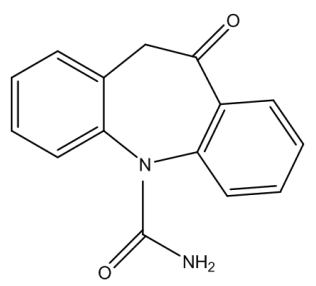

Scheme 1. Chemical structure of oxcarbazepine.

\footnotetext{
* Author to whom correspondence should be addressed. (E-mail: seletyilmaz@hotmail.com)
} 
biological samples without the need for extensive sample preparation, since there is no interference from the excipients and endogenous substances. ${ }^{12}$

There are two main objectives of this study. The first is to investigate the detailed electro-reduction behavior of oxcarbazepine based on its electroactive groups at GCE by CV and DPV techniques. The second is to develop new voltammetric techniques for fully validated, simple, selective, sensitive, rapid and low cost procedures for quantitative determination of oxcarbazepine in biological samples and pharmaceutical dosage forms without any time-consuming extraction or evaporation steps prior to drug assay. The proposed voltammetric techniques are more rapid and simpler than chromatography or spectrometry techniques.

\section{EXPERIMENTAL}

\section{Apparaturs}

A Model Metrohm 757 VA Trace Analyzer (Herisau, Switzerland) was used for the voltammetric measurements, with a three-electrode system consisting of glassy carbon working electrodes (GCE; $\varphi=3 \mathrm{~mm}$, Metrohm), a platinum wire auxiliary electrode and a $\mathrm{Ag} / \mathrm{AgCl}(\mathrm{KCl} 3 \mathrm{M}$, Metrohm) reference electrode. Before each measurement the glassy carbon working electrode was polished manually with polishing alumina (prepared from $\varphi=0.01 \mu \mathrm{m}$ aluminum oxide) on an alumina polish pad then rinsed with ultra pure deionized water and ethanol. Oxygen was removed from the supporting electrolyte solution by the passage of argon gas (analytically pure $99.99 \%$ ) for $5 \mathrm{~min}$ before all measurements. Furthermore, the argon gas was also passed through each sample solution for $60 \mathrm{~s}$ before each measurement. In each new experiment, a new bare electrode surface was used.

All $\mathrm{pH}$ measurements were made with a Model Metrohm $744 \mathrm{pH}$ meter (Herisau, Switzerland. All measurements were carried out at the temperature of the laboratory $\left(15-20{ }^{\circ} \mathrm{C}\right)$. For the analytical application, the following parameters were employed: pulse amplitude $50 \mathrm{mV}$; pulse time $0.04 \mathrm{~s}$, voltage step $0.009 \mathrm{~V}$, voltage step time 0.2 , scan rate in the range $10-1000 \mathrm{mVs}^{-1}(\mathrm{CV})$.

An Agilent 1100 model high performance liquid chromatography (HPLC) apparatus was used for the HPLC measurements, with an electrochemical detector.

\section{Drug and Chemicals}

For this study oxcarbazepine and its oxilepsi ${ }^{\circledR}$ tablet dosage forms were kindly supplied by Eczacibası (Istanbul, Turkey). A stock solution of $1.0 \times 10^{-2} \mathrm{M}$ was prepared by dissolving an accurate mass of the drug in an appropriate volume of ethanol kept in the refrigerator. The working solutions for the voltammetric investigations were prepared by dilution of the stock solution with ethanol. All solutions were protected from light and were used within $24 \mathrm{~h}$ to avoid decomposition. The $0.067 \mathrm{M}$ phosphate buffer, $\mathrm{pH} 4.50-7.50$ (sodium hydrogen phosphate, $\mathrm{Na}_{2} \mathrm{HPO} 4$, Riedel, Seelze, Germany and sodium dihydrogen phosphate, $\mathrm{NaH}_{2} \mathrm{PO}_{4}$, Riedel, Seelze, Germany), 0.2 M acetate buffer, $\mathrm{pH}$ 3.51-5.51 and 0.04 M Britton Robinson buffer, $\mathrm{pH}$ 2.09-12.00 (acetic acid, Riedel, Seelze, Germany, $100 \mathrm{~m} / \mathrm{m} \%$ + boric acid, Merck, Darmstadt, Germany + phosphoric acid, Carlo Erba, Rodeno, France, $85 \mathrm{~m} / \mathrm{m} \%$ ) were used for the supporting electrolyte solutions. DI water with $18.2 \mathrm{M} \Omega \mathrm{cm}^{-1}$ conductivity (Sartorius Arium model Water Systems) was used throughout the experiments. Other chemicals, all of analytical-reagent grade, (Merck) were used. Oxilepsi ${ }^{\circledR}$ tablets (Eczacibası, Inc, Istanbul, Turkey) were labeled to contain $300 \mathrm{mg}$ oxcarbazepine per tablet.

For the HPLC experiments, methanol (HPLC gradient, J. T. Baker, 8402), phosphoric acid (Riedel-de Haen, 30417) and bi-distilled water were used.

\section{Calibration Graph for Quantitative Determination}

Oxcarbazepine was dissolved in ethanol to obtain $1 \times 10^{-2} \mathrm{M}$ stock solution. This solution was diluted with ethanol to obtain diluted oxcarbazepine concentrations. For optimum conditions described in the experimental section, a linear calibration curve for DPV analysis was constructed in the oxcarbazepine concentration range $8 \times 10^{-6}-1 \times 10^{-4} \mathrm{M}$ for working electrode. The repeatability, accuracy and precision were checked.

\section{Working Voltammetric Procedure of Spiked Tablet Dosage Forms}

Ten tablets were weighed and ground to a fine powder and $1 \times 10^{-2} \mathrm{M}$ drug solution was prepared with ethanol. To eliminate interfering excipients other than pure drug, the contents of the tube were centrifuged to insoluble species left to precipitate for $20 \mathrm{~min}$ at $4000 \mathrm{rpm}$ to affect complete dissolution and then diluted to volume with the same solvent. Appropriate solutions were prepared by taking suitable aliquots of the clear supernatant liquor and diluting with selected supporting electrolyte solution. Each solution was transferred into the voltammetric cell and de-aerated with argon (analytically pure, $99.99 \%$ ) for 5 min before measurement.

\section{Working Voltammetric Procedure of Spiked Human Urine}

Urine obtained daily from a volunteer was diluted to the ratio $1: 9$ with ethanol. Firstly, $9.4 \mathrm{~mL} 0.04 \mathrm{M} \mathrm{BR}(\mathrm{pH}$ 8.02) was put into the voltammetric cell and its voltammogram was recorded as a blank. Then $600 \mu \mathrm{L}$ 
of the diluted urine solution was added to this solution and its voltammogram was recorded as an urine blank. After that $40 \mu \mathrm{L}$ urine sample $\left(1 \times 10^{-2} \mathrm{M}\right.$ oxcarbazepine solution in urine) was added to the same solution, its voltammogram was recorded. Then $20 \mu \mathrm{L}$ of $1 \times 10^{-2} \mathrm{M}$ oxcarbazepine solution was added three times and their voltammograms were recorded after every addition.

\section{RESULTS AND DISCUSSION}

\section{Electrochemical Reduction Behavior of Oxcarbazepine}

There is no detailed electrochemical study in which the reduction process of oxcarbazepine and its determination at GCE has been studied so far. Therefore, the electrochemical reduction process and the determination using this electrode were firstly carried out by $\mathrm{CV}$ and DPV techniques. CV measurements performed with oxcarbazepine solution of $1 \times 10^{-4} \mathrm{M}$ at GCE in different buffers are given in Figure 1a-d.

The reduction peak of oxcarbazepine appeared in $0.04 \mathrm{M}$ Britton-Robinson (BR) buffer, $\mathrm{pH}$ 8.05-10.04 (Fig. 1a, b) and $0.067 \mathrm{M}$ phosphate buffer, $\mathrm{pH} 4.50$ 7.50 (Fig. 1d), while the peak disappeared in $0.2 \mathrm{M}$ acetate buffer, $\mathrm{pH} 3.51-5.51$ (Figure 1c).

The effects of various potential scan rates between $10-1000 \mathrm{mVs}^{-1}$ on the peak potential and the peak current of $1 \times 10^{-4} \mathrm{M}$ oxcarbazepine $(\mathrm{pH}$ 8.05) were evaluated (Figure 2).

A negative shift in the peak potential confirmed the reversibility of the reduction process. ${ }^{20-21}$ Potential scan rate studies were then performed to assess whether the processes on GCE were under diffusion- or adsorption-control. $^{9-23}$ We employed two tests for this procedure. The relationship existing between peak current and scan rate between $10-1000 \mathrm{mVs}^{-1}$ are as follows:

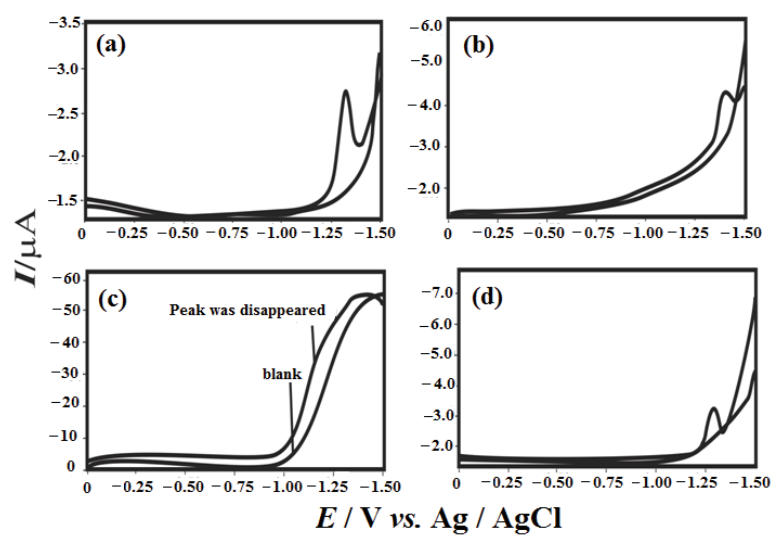

Figure 1. Selected cyclic voltammograms of $1 \times 10^{-4} \mathrm{M}$ oxcarbazepine in (a) $0.04 \mathrm{M} \mathrm{BR}(\mathrm{pH} 8.05$ ); (b) $0.04 \mathrm{M} \mathrm{BR}$ (pH 10.04); (c) $0.2 \mathrm{M}$ acetate (pH 4.76); and (d) $0.067 \mathrm{M}$ phosphate (pH 7.39) buffers on GCE. Scan rate: $100 \mathrm{mVs}^{-1}$.

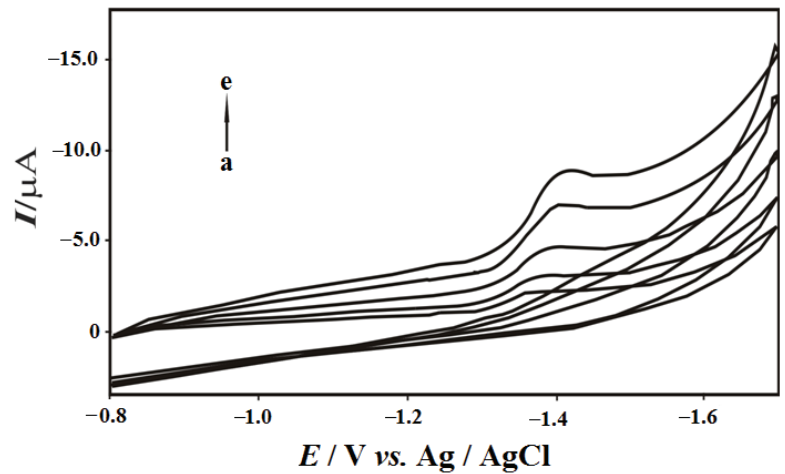

Figure 2. Cyclic voltammograms of $1 \times 10^{-4} \mathrm{M}$ oxcarbazepine in chosen $0.04 \mathrm{M}$ Britton-Robinson (BR) buffer ( $\mathrm{pH} 8.05$ ) at GCE. Scan rates: (a) 50; (b) 100; (c) 250; ; (d) 600; and (e) $1000 \mathrm{mVs}^{-1}$.

$$
I_{\mathrm{p}} / \mu \mathrm{A}=0.0658 v^{1 / 2} / \mathrm{mV} \mathrm{s}^{-1}+0.027
$$

(correlation coefficient, $r=0.995$ )

$$
\begin{aligned}
& \log \left(I_{\mathrm{p}} / \mu \mathrm{A}\right)=0.4846 \log \left(v / \mathrm{mV} \mathrm{s}^{-1}\right)-1.1313 \\
& r=0.999
\end{aligned}
$$

From both equations, correlation coefficient and slope were 0.995 and 0.4846 respectively. These values indicate that the electrode reaction was diffusioncontrolled. ${ }^{9-20}$ Therefore, a diffusion component must be taken into account. Other studies were conducted in line with this phenomenon.

Next, in order to obtain the optimum experimental conditions for the analytical application, the influence of $\mathrm{pH}$ on peak current and peak potential in the range of $\mathrm{pH} 4.50-11.15$ were studied in different buffers at GCE by $\mathrm{CV}$ and DPV techniques. All the graphics obtained from CV and DPV were found to be similar. For this reason, only DPV results are given as $I v s$. $\mathrm{pH}$ and $E v s$. $\mathrm{pH}$ plots in Figure $3 \mathrm{a}$ and Figure $3 \mathrm{~b}$ for GCE.

The peak current $\left(i_{\mathrm{p}}\right)$ versus $\mathrm{pH}$ plot shows that the peak current was maximum and the shape of curve was better in $0.04 \mathrm{M} \mathrm{BR}(\mathrm{pH} 8.05)$ buffer (Figure 3a). For this reason, 0.04 M BR buffer ( $\mathrm{pH}$ 8.05) was chosen due to the sharp response and better peak shape for the calibration of pharmaceutical dosage form and urine samples. $^{20,21}$ The voltammetric response was strongly $\mathrm{pH}$ dependent. The $i_{\mathrm{p}}$ changed in the range of $\mathrm{pH} 5.0-10.0$. $I_{\mathrm{p}}$ increased with $\mathrm{pH}$ from about 5.0 to 10.0 , while it decreased after about $\mathrm{pH}$ 10.0. No peak appeared below pH 5.0 (Figure 1c) and above 10.0. The cathodic peak potential slightly shifted to less negative values with increasing $\mathrm{pH}$ (Figure 3b). These can also be explained by changes in protonation of the acid-base functions in the oxcarbazepine molecules (Scheme 2). ${ }^{20,21}$ 


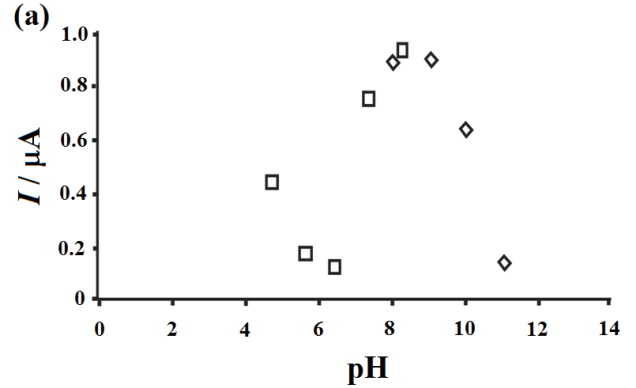

(b)

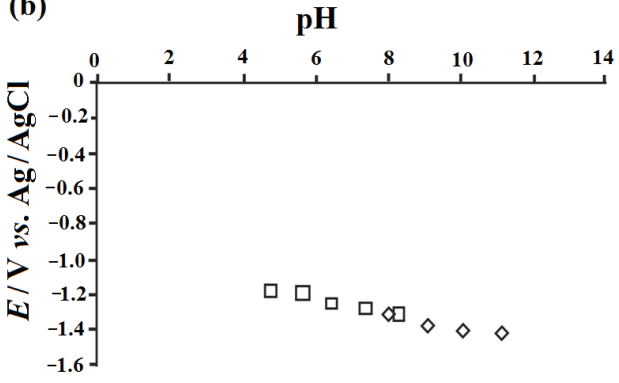

Figure 3. Effect of $\mathrm{pH}$ on $5 \times 10^{-5} \mathrm{M}$ oxcarbazepine DPV (a) peak current; and (b) peak potential; ( $\square$ ) phosphate $(0.067 \mathrm{M})$ and $(\diamond)$ Britton-Robinson buffers $(0.04 \mathrm{M})$.

\section{Reduction Mechanism of the Electrode Reaction}

When describing electrochemical reactions, an "E" and "C" formalism is often employed. ${ }^{19}$ The E represents an electron transfer; sometimes $E_{O}$ and $E_{R}$ are used to represent oxidations and reductions respectively. The $\mathrm{C}$ represents a chemical reaction which can be any elementary reaction step and is often called a "following" reaction.

As can be seen from the reduction mechanism, in the first stage there is a negative attack of the electron to positive carbon atom. The negative charge of the electron on the electrode affects the carbon atom and carbon radical forms. Then one electron of carbon in the carbon-oxygen bonds is repelled entirely onto the oxygen, giving it a negative charge. The negative oxygen ion takes a hydrogen ion from a water molecule or the acid in the solution in the second stage of the reaction. In the third step, this radical carbon atom takes one more electron and carbonium occurs. In the last step, carbonium takes a $\mathrm{H}^{+}$ion from the solution with the reaction $\mathrm{C}$ and then alcohol forms. ${ }^{19}$

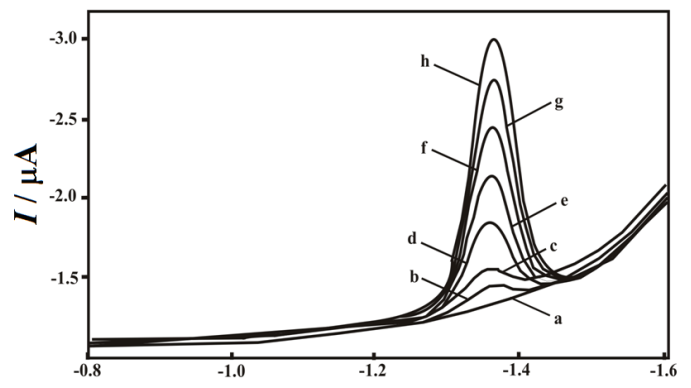

E/V vs. Ag/ AgCl

Figure 4. The calibration voltammograms at different concentrations $(\mathrm{b}-\mathrm{h})$ of oxcarbazepine at GCE by DPV; (a) supporting electrolyte (0.04 M BR buffer, $\mathrm{pH} 8.05$ ); (b) $8.0 \times 10^{-6}$; (c) $1.0 \times 10^{-5}$; (d) $3.0 \times 10^{-5}$; (e) $5.0 \times 10^{-5}$; (f) $7.0 \times 10^{-5}$; (g) $9.0 \times 10^{-5}$; and (h) $1.0 \times 10^{-4} \mathrm{~mol} \mathrm{dm}^{-3}$ oxcarbazepine.

\section{Validation Parameters for the Quantitative Analysis}

On the basis of the electrochemical reduction of oxcarbazepine, DPV techniques were used to develop the quantitative determination of the pure active material in spiked human urine and drug. The optimum experimental conditions were chosen from studies of the variation of the peak current on pulse amplitude and potential step. Using the optimum conditions described in the experimental section, the voltammograms for various concentrations of oxcarbazepine were recorded in $0.04 \mathrm{M}$ BR buffer ( $\mathrm{pH} 8.05$ ) on GCE by applied DPV technique (Figure 4).

Quantitative evaluation based on the linear correlation between the reduction peak current and concentration was carried out. As a result of this, good correlations were obtained for oxcarbazepine in the concentration range of $8 \times 10^{-6}$ to $1 \times 10^{-4} \mathrm{M}$ on GCE. Related equations for the plot of the logarithm of the reduction peak current versus the logarithm of the regression parameters of the calibration curve obtained from ten DPV measurements are given in Table 1.

Validation of the procedure for the quantitative determination of the oxcarbazepine was examined via evaluation of the limit of detection (LOD), limit of quantification (LOQ), precision: repeatability (intraday), reproducibility (interday) and accuracy by DPV technique (Table 1) ${ }^{9-24}$.

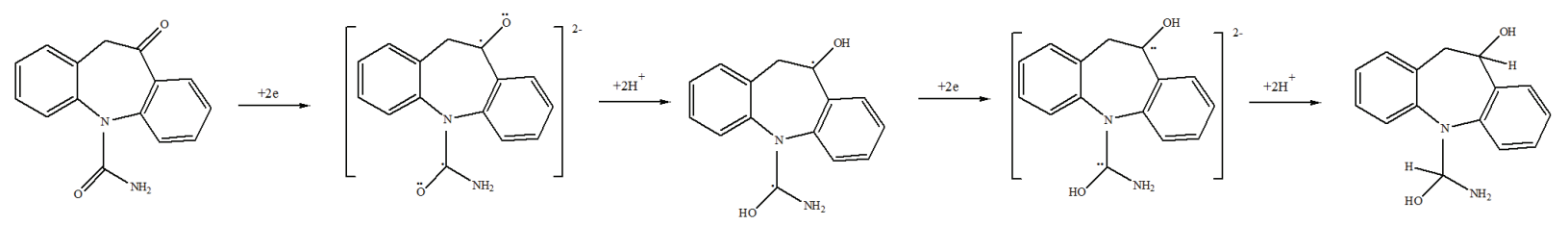

Scheme 2. The possible mechanism of the electrochemical reduction of oxcarbazepine. 
Table 1. Quantitative analysis parameters of oxcarbazepine obtained from calibration plots in BR solution $(\mathrm{pH}$ 8.05) at GCE by DPV technique

\begin{tabular}{lc}
\hline \multicolumn{1}{c}{ Parameters } & Results \\
\hline Measured potential, $E / \mathrm{V}$ & -1.32 \\
Linear concentration range / M & $8 \times 10^{-6}-1 \times 10^{-4}$ \\
Slope / mA M & $1.67 \times 10^{4}$ \\
\pm S.D. of slope & 0.042 \\
Intercept / nA & 0.06 \\
\pm S.D. of intercept & 0.013 \\
Correlation coefficient, $r$ & 0.999 \\
Number of measurements, $n$ & 5 \\
LOD / M & $1.65 \times 10^{-6}$ \\
LOQ/ M & $5.51 \times 10^{-6}$ \\
$\begin{array}{l}\text { R.S.D of repeatability of peak current } \\
\text { (intraday) / \% }\end{array}$ & $2.43^{\text {(a) }}$ \\
$\begin{array}{l}\text { R.S.D of reproducibility of peak } \\
\text { current (interday) } / \%\end{array}$ & $1.51^{\text {(a) }}$ \\
$\begin{array}{l}\text { R.S.D of repeatability of peak } \\
\text { potential (intraday) } / \%\end{array}$ & $1.85^{\text {(a) }}$ \\
$\begin{array}{l}\text { R.S.D of reproducibility of peak } \\
\text { potential (interday) } / \%\end{array}$ & $0.51^{\text {(a) }}$ \\
\hline (a) Concentration: $5 \times 10^{-5} \mathrm{M}$. & \\
\hline
\end{tabular}

LOD and LOQ were calculated on the electroreduction peak current using the following equations: $\mathrm{LOD}=3 \mathrm{~s} / \mathrm{m}$, LOQ $=10 \mathrm{~s} / \mathrm{m}$ ( $\mathrm{s}$ is the standard deviation of the peak current over five runs, $m$ is the slope of the calibration curve). ${ }^{9-24}$ The achieved LOD and LOQ were $1.65 \times 10^{-6}$ and $5.51 \times 10^{-6} \mathrm{M}$ for GCE respectively. The repeatability and reproducibility of the current measurement were calculated by DPV technique from ten independent runs as 2.43 and $0.41 \%$ R.S.D. respectively for $5 \times 10^{-5} \mathrm{M}$ oxcarbazepine on GCE. The repeatability and reproducibility of the peak potential measurement were also calculated by DPV technique from ten independent runs as 1.85 and $0.51 \%$ R.S.D. respectively for $5 \times 10^{-5} \mathrm{M}$ oxcarbazepine on GCE.

Table 2. The assay of found oxcarbazepine in commercial oxilepsi ${ }^{\circledR}$ and mean recoveries of spiked oxcarbazepine in oxilepsi drug tablets on GCE by DPV technique

\begin{tabular}{lc}
\hline $\begin{array}{l}\text { Labeled claim of oxcarbazepine in oxilepsi } \\
\text { drug /mg }\end{array}$ & 300 \\
\hline Amount of oxcarbazepine found / mg & 314.90 \\
R.S.D. of amount found / \% & 1.29 \\
Bias / \% & 4.96 \\
Spiked oxcarbazepine to oxilepsi drug / mg & 50.00 \\
Found spiked oxcarbazepine / mg & 48.79 \\
Recovery of found oxcarbazepine / \% & 97.6 \\
R.S.D. of recovery / \% & 1.47 \\
Bias / \% & 2.40 \\
\hline
\end{tabular}

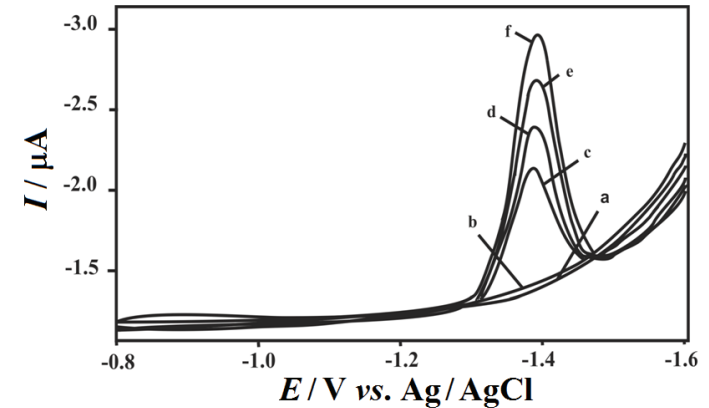

Figure 5. Differential pulse voltammograms of oxcarbazepine in spiked urine samples (a) supporting electrolyte $(0.04 \mathrm{M}$ BR, $\mathrm{pH} 8.05)$; (b) $9.4 \mathrm{~mL} \mathrm{a}+0.6 \mu \mathrm{L}$ diluted urine $(1 \mathrm{~mL}$ urine + $9 \mathrm{~mL}$ ethanol); (c) $4 \times 10^{-5}$ oxcarbazepine with urine; (d) $2 \times 10^{-5}$; (e) $4 \times 10^{-5}$; and (f) $6 \times 10^{-5} \mathrm{M}$ oxcarbazepine.

\section{Pharmaceutical Applications}

The amount of oxcarbazepine in commercial tablets was calculated by reference to the appropriate calibration plots (Table 2).

As can be seen from Table 2, the proposed techniques could be successfully applied to oxcarbazepine assay in tablets without any interference. As far as we are aware there is no official technique in the pharmacopoeias or other literature describing the determination of oxcarbazepine in human urine and pharmaceutical dosage forms. For this reason, the proposed techniques were checked by performing recovery tests. To determine whether excipients in the tablets interfered with the analysis, the accuracy of the proposed methods were evaluated by recovery tests after the addition of a certain amount of pure drug to pre-analyzed formulations of oxcarbazepine (Table 3).

DPV voltammograms of oxcarbazepine in spiked urine samples are given in Figure 5.

As can be seen in Figure 5, no extra reduction peak and noise peaks appeared in the biological matrix (human urine). The recovery studies were also carried out in human urine (Table 3 ).

The results showed the validity of the proposed techniques for the quantitative determination of oxcarbazepine in human urine and tablets. The proposed DPV technique proved to be sufficiently precise and

Table 3. The recovery amount of oxcarbazepine in spiked human urine on GCE by DPV technique

\begin{tabular}{lc}
\hline Medium & Human urine \\
\hline Oxcarbazepine added / M & $4 \times 10^{-5}$ \\
Oxcarbazepine found / M & $4.01 \times 10^{-5}$ \\
Number of measurements, $n$ & 5 \\
Average recovery / \% & 100.25 \\
R.S.D. / \% & 0.42 \\
Bias / \% & 0.25 \\
\hline
\end{tabular}


accurate for reliable electro analytical analysis of oxcarbazepine.

\section{Chromatographic Studies}

Chromatographic techniques are a good alternative to the proposed voltammetric techniques for drug analysis. Optimization of the chromatographic resolution of ionogenic compounds by chromatographic techniques has been actively researched. Due to the specific ionization characteristics of this solute, the two most useful optimization parameters are the $\mathrm{pH}$ and organic modifier content of the mobile phase. For ionizable compounds, since changes in solvent content of the mobile phase affect the retention behavior, optimization of this compound is often carried out at fixed $\mathrm{pH}^{25}$ This study focuses mainly on the organic modifier effect of the mobile phase on the chromatographic behavior of oxcarbazepine.

The HPLC system is an Agilent 1100 series (Agilent Technologies, USA), including a quaternary solvent delivery pump, a thermostat column compartment with HP 1049 A - programmable electrochemical detector (ECD) and a manual sample injection valve with a $20 \mu \mathrm{L}$ loop. Chromatographic separation was carried out using a Zorbax Eclipse XDB-C 8 (150 mm $\times$ $4.6 \mathrm{~mm}$ i.d., $5 \mu \mathrm{m}$ ) column. Methanol (HPLC gradient, J.T. Baker 8402), o-phosphoric acid (Redel-de Haen 30417) and bi-distilled water were used for the mobile phase. Distilled water was used after being filtered through $0.22 \mu \mathrm{m}$ pore diameter Millipore Express $($ PVDF vacuum filter unit.

Good correlations were obtained for oxcarbazepine in the concentration range of $7.7 \times 10^{-6}-7.7 \times 10^{-4} \mathrm{M}$ using the HPLC tehnique. Some validation parameters for the quantitative determination of the oxcarbazepine were examined via evaluation of the limit of detection (LOD) and limit of quantification (LOQ) (Table 4).

LOD and LOQ were calculated using the following equations: $\mathrm{LOD}=3 \mathrm{~s} / \mathrm{m}, \mathrm{LOQ}=10 \mathrm{~s} / \mathrm{m}$. The achieved LOD and LOQ were $4.70 \times 10^{-6}$ and $6.71 \times 10^{-6} \mathrm{M}$ for GCE respectively. The results of

Table 4. The results of voltammetric analysis compared with high performance liquid chromatography (HPLC) technique

\begin{tabular}{lcc}
\hline Parameters & Voltammetry & HPLC \\
\hline Linear concentration & $8 \times 10^{-6}-$ & $7.7 \times 10^{-6}-$ \\
range / M & $1 \times 10^{-4}$ & $7.7 \times 10^{-4}$ \\
LOD / M & $1.65 \times 10^{-6}$ & $4.70 \times 10^{-6}$ \\
LOQ / M & $5.51 \times 10^{-6}$ & $6.71 \times 10^{-6}$ \\
$\begin{array}{l}\text { Labeled amount of } \\
\text { oxcarbazepine }\end{array}$ & 300 & 300 \\
$\begin{array}{l}\text { inoxilepsi drug / mg } \\
\text { Amount of oxcarbaze- } \\
\text { pine found / mg }\end{array}$ & 314.90 & 315.20 \\
$\begin{array}{l}\text { R.S.D. of amount } \\
\text { found / \% }\end{array}$ & 1.29 & 3.20 \\
\hline
\end{tabular}

voltammetric analysis were compared with the high performance liquid chromatography (HPLC) technique (Table 4).

As shown in Table 4, voltammetry results were identical to the HPLC results. This indicates the accuracy of proposed voltammetry technique.

\section{CONCLUSION}

As far as we know, in this work, the determination of oxcarbazepine in human urine and in tablet form based on its electrochemical reduction on GCE was studied by voltammetric techniques for the first time. Good recoveries $(97.6 \%)$ indicated excipients do not interfere with the analysis.

The principal advantage of these proposed techniques over other techniques is that they may be applied directly to the analysis of pharmaceutical dosage forms and to biological samples without the need for extensive sample preparation, since there was no interference from excipients or endogenous substances. Another advantage is that the developed techniques are rapid, requiring about 5 min to run any sample and involves no sample preparation other than dissolving, diluting, precipitating, centrifuging and transferring an aliquot to the supporting electrolyte. This paper is not intended to be a study of the pharmacodynamic properties of oxcarbazepine because only healthy volunteers were used for sample collection and results might be of no significance. It only indicates the possibility of monitoring this compound which makes the technique useful for pharmacokinetic and pharmacodynamic purposes. ${ }^{9-18,21}$ In addition to all of the above, the proposed techniques might be a rapid and simple alternative to more complicated chromatographic (HPLC) or spectrometric (UV) techniques for routine analysis of oxcarbazepine in any medium where considerably little interference takes place.

Acknowledgements. We would like to thank Eczacıbaş1 Inc. (Istanbul, Turkey) for supplying pure oxcarbazepine and its oxileps tablet dosage forms for developing the proposed voltammetric techniques.

\section{REFERENCES}

1. C. Encarnaci'on Burgoa, M. O. D Renedo, and M. Julia Arcos Mart'inez, J. Pharm. Biomed. Anal. 43 (2007) 1156-1160.

2. S Binel, Master thesis of Çanakkale Onsekiz Mart University, Institute for Natural \& Applied Sciences (2009) Canakkale, Turkey.

3. F. Bugamelli, C. Sabbioni, R. Mandrioli, E. Kenndler, F. Albani, and M.A Raggi, Anal. Chim. Acta 472 (2002) 1-2.

4. M. Coutin, M. Balboni, E. Callegati, C. Candela, F. Albani, R. Riva, and A. Baruzzi, J. Chromatogr. B 828 (2005) 113-117.

5. E. Greiner-Sosanko, S. Giannoutsos, R. L. Darla, A. V. Mohamed, and D.M. Krasowski, J Chromatogr Sci. 45 (2007) 
616-622.

6. H. Breton, M. Cociglio, F. Bressolle, H. Peyriere, J. Blayac, and D. Hillaire-Buys, J. Chromatogr. B 828 (2005) 80-90.

7. K. M. Klys, S. Rojek, and F. Bolechala, J. Chromatogr. B $\mathbf{8 2 5}$ (2005) 38-46. C. S. Ramaa, P. Chothe, A. A Naik, and V. J. Kadam, Indian J. Pharm. Sci. 68 (2006) 265-266.

9. S. Yilmaz, B. Uslu, and S. A. Ozkan, Talanta 54 (2001) 351-360.

10. B. Uslu, S. Yllmaz, and S. Özkan, Pharmazie 56 (2001) 629-632.

11. T. Demircigil, S. A. Özkan, Ö, Çoruh, and S. Yılmaz, Electroanalysis 14 (2002) 122-127.

12. S. A. Ozkan and B. Uslu, Anal. Bioanal. Chem. 372 (2002) $582-586$

13. M. Çıtak, S. Yılmaz, Y. Dilgin, G. Türker, S. Yagmur, H. Erdugan, and N. Erdugan, Curr. Pharm. Anal. 3 (2007) 141-145.

14. S. Skrzypek, W. Ciesielski, and S. Yilmaz, Chem. Anal. (Warsaw) 52 (2007) 1071-1078.
15. S. Yılmaz, S. Skrzypek, Y. Dilgin, S. Yagmur, and M. Coskun, Curr. Anal. Chem. 3 (2007) 41-46.

16. S. Yilmaz, M. Sadikoglu, G. Saglikoglu, S. Yagmur, and G. Aksin, Int. J. Electrochem. Sci. 3 (2008) 1534-1542.

17. S. Y1lmaz, Colloids Surf., B 71 (2009) 79-83.

18. M. Sadikoglu, G. Saglikoglu, S. Yagmur, E. Orta, and S. Yilmaz, Curr. Anal. Chem. 7 (2011) 130-135.

19. R. A. Marcus, J. Phys. Chem. 67 (1963) 853-857.

20. B. Uslu and S. A. Ozkan, Electrochim. Acta 49 (2004) 4321-4329.

21. B. Uslu and S. A. Ozkan, Electroanalysis 17 (2005) 2074-2083.

22. P. J. Elving and J. T. Leone, J. Am. Chem. Soc. 80 (1958) 1021-1029.

23. S. Shorvon, Seizure-Eur. J. Epiepl. 9 (2000) 75-79.

24. S. A. Ozkan, Electroanalytical Methods In Pharmaceutical Analysis And Their Validation, ISBN:978-0-9664286-7-4

25. E. Çubuk Demiralay, M. Gümüştaş, and H. Canbay, Pharmacie Globale, Int. J. Comprehens, Pharm. 6 (2011) 1-4. 